\title{
Ensayo de una Tipología de la Literatura Fantástica
}

\author{
(A propósito de la literatura hispanoamericana)
}

Mi centro de interés en este trabajo es deslindar el subgénero "literatura fantástica" y destacar algunos de sus rasgos caracterizadores, a propósito de la narrativa hispanoamericana, tan rica en obras de esa indole.

Tzvetan Todorov ha planteado el problema por primera vez en forma sistemática en su libro Introduction à la lintérature fantastique, (Pa. ris: Seuil, 1970). Aunque disentimos en la solución que le ha dado, es necesario reconocerle el mérito de haber establecido claramente ciertas categorias y una metodología de rasgos contrastivos con distinción de niveles de análisis; con ello marca un adelanto importante en su estudio, a partir del cual pueden intentarse otras soluciones.

Resulta, pues, imprescindible exponer brevemente el sistema de Todorov para recordar sus rasgos esenciales y cotejarlos con la categorización que proponemos.

Todorov delimita el género de lo fantástico con dos sistemas de oposiciones:

1) El lector se interroga sobre la naturaleza del texto y según ella quedan establecidas dos parejas contrastivas:

\section{Literatura Fantástica / poesía LIRERATURA FANTÁSTICA / ALEGORÍA}

La primera pareja está separada por la noción de obra referencial, descriptiva o representativa, pero no en el sentido de que la obra tenga un referente externo, sino de que internamente el texto sea referencial o representativo, es decir que su lenguaje sea trasparente y remita de las palabras a los hechos. Para Todorov no hay nunca poesía fantástica 
porque no se da ese pasaje y no se produce en el lector una reacción ante los hechos tal como se experimentan en el mundo, lo cual es indispensable en la literatura fantástica para que se los pueda clasificar de naturales o sobrenaturales. ${ }^{1}$

La segunda pareja está separada porque el texto tenga o no una doble significación: sentido literal y sentido trópico o traslaticio. También aquí debe darse la distinción en el interior de la obra en forma inequívoca, y no depender del capricho interpretativo del lector. Esto se refuerza con el concepto de que la alegoría es mortal para lo fantástico, generalmente, pero que puede haber grados de supervivencia del sentido literal y, por lo tanto, de ingreso de lo fantástico en el género alegórico, aunque lo fantástico tienda a desaparecer en contacto con lo alegórico.

2) La otra distinción importante establecida por Todorov consiste en que el lector se interroga sobre la naturaleza de los acontecimientos relatados, y en este caso se establece una tripartición:

\section{Lo eXtraordinario / Lo FANTÁstico / Lo MARAVILLOSO}

Las tres clases están determinadas con dos parámetros: la existencia de hechos normales o a-normales en el relato, y la explicación de lo a-normal. Si se mantiene la duda sobre la naturaleza de los acontecimientos que salen de lo normal estamos en el ámbito de la literatura fantástica, si se disipa la duda caemos en lo extraordinario (cuando a pesar de su rareza se los inscribe entre los hechos naturales) y en lo maravilloso (cuando se los adjudica al orbe de lo sobrenatural e irreal).

Frente a este planteo de Todorov of recemos una solución diferente, que luego cotejaremos con la suya, discutiendo los pro y los contra de ambas.

Para salvar algunos de los inconvenientes que encontramos a su caracterización proponemos otra en la que:

1) No se plantea el problema de oposición con lo poético y con lo alegórico puesto que ya explicaremos luego que las consideramos categorías de dos sistemas que se cruzan pero que no se excluyen.

2) Proponemos para la determinación de qué es lo fantástico, su inclusión en un sistema de tres categorías construido con dos parámetros: la existencia implícita o explícita de hechos a-normales, a-naturales o irreales y sus contrarios; y además la problematización o no problematización de este contraste. Aclaro bien: la problematización de su

\footnotetext{
1 Véase op. cit., pp. 64-66 para precisar este concepto de Todorov.
} 
convivencia (in absentia o in praesentia) y no la duda acerca de su naturaleza, que era la base de Todorov. Así se forman las subclases de:

Contraste de lo A-NORMaL / LO NORMAL SOlo Lo NO A-NORMaL

Como Problema

Lo fantástico

\section{Sin Problema}

Lo maravilloso
Lo posible ${ }^{2}$

Así la literatura fantástica quedaría definida como la que presenta en forma de problema hechos a-normales, a-naturales o irreales. Pertenecen a ella las obras que ponen el centro de interés en la violación del orden terreno, natural o lógico, y por lo tanto en la confrontación de uno y otro orden dentro del texto, en forma explícita o implícita.

Expuestas la solución de Todorov y la nuestra, entraremos en su discusión. A las primeras oposiciones propuestas por Todorov: LITERATURA FANTÁSTICA / POESÍA y LITERATURA FANTÁSTICA / ALEgORÍA, les encontramos el inconveniente de que no parecen categorias exclusivas sino cruzadas. Quizás en ciertas épocas de la historia de la literatura lo han sido, pero no en todas. Es verdad que Ja literatura fantástica debe tener como soporte indispensable un arte representativo, puesto que si la hemos basado en el contraste de hechos anormales y normales, necesita ser representativa de esos hechos. Sin embargo, no siempre la poesía ha sido no-representativa. Pensemos, por ejemplo, en los poemas de Borges, "El Golem" o "La noche cíclica" y veremos que pocos durarían en asignarlos al subgénero "poesía fantástica". Esta rigidez de exclusiones genéricas, buena para ciertas épocas de clases literarias muy definidas, no resulta aplicable a la literatura contemporánea que construye géneros híbridos o con caracteres más fluctuantes. Por eso nos parece más apropiada una metodología que establezca oposiciones de rasgos nítidos pero que permita cruzarlos: p. ej. LITERATURA REPRESENTATIVA / NO REPRESENTATIVA; LITERATURA DE SIGNIFICADO SOLO LITERAL / DE SIGNIFICADO TAMBIÉN TRÓPICO.

Si tomamos la primera pareja podría incluirse poesía, drama - no mencionado por Todorov-y ficción dentro de la literatura representativa, y en ella cabrían la poesía, el drama o la ficción fantástica. Pienso, para el drama fantástico, en Rbinoceros, Amedée ou comment s'en

2 La práctica de la literatura y la crítica no han acuñado un nombre genérico para lo que no es a-normal: el término "realista" no abarcaría buena parte de la narrativa que cae dentro de los cuadros de "lo posible" (término que nosotros sugetimos). No comprendería la novela idealista, la naturalista, la de acontecimientos extraordinarios pero no irreales, etc. 
debarrasser de Ionesco o en Las paredes, de la argentina Graciela Gámbaro.

Borges es un ejemplo extremo de que para él no hay aparentemente género que no pueda alojar lo fantástico. Recordemos su dedicatoria de El Hacedor, "A Leopoldo Lugones", 3 donde en un sueño convive él mismo con el viejo poeta, juntando tiempos y espacios diferentes. Ocurre algo semejante con el ensayo "El sueño de Coleridge" de Otras inquisiciones, donde para explicar las imaginaciones (también alejadas en tiempo y espacio) del Emperador Kublai Kan, que soñó el palacio y ordenó construirlo, y de Coleridge, que soñó un poema sobre el palacio, da una serie de causas naturales y sobrenaturales hasta llegar a la última, que postula el ingreso en la tierra de un objeto soñado por otros, como en el cuento "Tlön, Uqbar, Orbis Tertius"."

Este método que emplea matrices de rasgos nos permitirá también sortear el problema de lo alegórico como excluyente de lo fantástico. Es verdad que Todorov no llega a hablar de exclusión sistemática, sino que afirma que la aparición de la significación alegórica es mortal para lo fantástico y puede llegar a eliminarlo totalmente. ${ }^{5}$

Creo que las razones que llevaron a Todorov a marcar la oposición LITERATURA FANTÁstica / ALEgoría, surgieron de la alegoría clásica, la cual nunca elegía para el nivel literal la narración de hechos fantásticos, manejándose preferentemente con hechos maravillosos, aunque alguna vez trabajase sólo con hechos reales. Además, en épocas anteriores quedaba la traslación de sentido muy clara porque se conocía la "gramática" que regía la alegoría o porque se incluía al final su explicación detallada, cosa que se justificaba porque la función de la alegoría era fundamentalmente didáctica. Pero ahora existe la tendencia a usar también lo fantástico para el nivel literal de estas obras, y además, a dejar poco explícita la función alegórica, simbólica o parabólica, es decir su significado no literal.

3 De acuerdo con el criterio de Todorov no lo sería porque el autor explicita que se trata de un sueño, pero sí lo es para nuestra definición, porque se centra el interés en ese encuentro de personas pertenecientes a tiempos y espacios distintos.

4 Podria argüirse que Borges es un escritor que viola las clasificaciones genéricas: p. ej. es autor de esos híbridos que participan de la naturaleza del cuento y del ensayo, tanto que alguno apareció en volúmenes dedicados a otro género ("El acercamiento a Almotásim", que es un cuento, en Historia de la Eternidad, que es un volumen de ensayos).

5 Así habla de grados en los valores alegóricos: alegoría evidente, con moraleja (fábulas, cuentos de Perrault), indirecta (La piel de zapa de Balzac), dudosa ("William Wilson" de Poe), ilusoria ("La nariz" de Gogol), pp. 78-79. 
Las condiciones impuestas por Todorov eliminarían buena parte de la literatura fantástica contemporánea; en cambio nuestro enfoque permite retener las obras de sentido traslaticio explícito o implícito, siempre que en el plano literal aparezca el contraste de lo real y lo irreal centrado como problema, aun cuando el sentido traslaticio lo resuelva o lo borre. Así se explica también que -contra la opinión de Todorovse vea el caso de qua lo alegórico refuerce el nivel literal fantástico en lugar de debilitarlo, porque el contenido alegórico de la literatura contemporánea es a menudo el sin sentido del mundo, su naturaleza problemática, caótica e irreal. Eso se ve claramente en "El zapallo que se hizo cosmos" del argentino Macedonio Fernández, donde está explicito el significado traslaticio del texto fantástico, o en otras obras donde no se declara cuál es la alegotia pero queda implícita por señales que lleva el texto. Así en "El prodigioso miligramo" del mejicano Juan José Arreola, en "La casa de Asterión", "La biblioteca de Babel" o "La lotería en Babilonia" de Jorge Luis Borges, o en "Tareas de salvamento" del cubano José Lozano Fuentes (que desarrolla un tema tradicionalmente alegórico, el viaje a los infiernos). ${ }^{6}$

A la clasificación de Todorov en fantástico / Maravilloso / EXTRAORDINARIo le encontramos el inconveniente menor de no ser exhaustiva (lo cual podría obviarse), porque no menciona una categoría que pueda incluir los relatos de lo normal, lo real, lo natural. Pero sobre todo resulta insatisfactoria por estar basada en la oposición de rasgos DUDA / DISIPACrón DE LA DUDA, que los mismos cultores del género no encuentran esencial. Un gran sector de obras contemporáneas no se plantea siquiera la duda y ellos admiten desde la primera línea el orden de lo sobrenatural, sin por eso permitir que se las clasifique como maravillosas.

Además los requisitos de Todorov hacen que sólo haya un período histórico muy reducido en el que florece la literatura fantástica pura (desde fines del xvil con Cazotte, hasta fines del XIx con Maupassant $^{7}$ y que sólo un escaso número de obras pertenezcan en su totalidad a dicho género porque la mayoría cae en lo maravilloso o en lo extraordinario en cuanto se introduce una explicación segura en el relato.

- Por ejemplo, no pondriamos Adán Buenosaires de Leopoldo Marechal, porque su viaje a los infiernos no implica una confrontación entre el orden de lo natural y lo sobrenatural; en cambio si aparece el problema en "Tareas de salvamento", como en el relato de May Sinclair, "Donde su fuego nunca se apaga" (incluido por J. L. Borges, S. Ocampo y A. Bioy Casares en su Anto. logía de la literatura fantástica, Buenos Aires, Sudamericana, 1940, ply 24. 252) o en "El converso" de Juan José Arreola.

7 Op. cit. pp. 174-175. 
Con nuestra propuesta se resuelve, por una parte, la inestabilidad del género, "categoría siempre evanescente", que el mismo Todorov reconoce y justifica con la comparación con el presente. Por otra, se amplía más el cuadro de lo fantástico, permitiendo incluir obras marginadas por su teoría, pero consideradas dentro del género por un consenso que parece justificado. ${ }^{8}$ Ello ocurre porque eliminamos la exigencia de mantener dudosa la explicación y aun la de ofrecer una explicación. Es indudable que al of recer una explicación ya se pone en el foco de interés el problema que consideramos como rasgo del género, y que al dejar la explicación en suspenso (sin inclinarse por ninguna solución) se refuerza el efecto de focalización. Pero que estas obras resulten peculiares del grupo analizado, no quiere decir que no haya otros medios de producir el mismo efecto, quizás más sutiles, y alcanzar así esa finalidad de conmoción (intelectual y emocional), ante el orden violado, dejando las señales de la violación en el texto.

Eliminada la exigencia de la explicación, veamos cuáles pueden ser los modos de destacar el carácter central de subversión del orden racional, con sentido problemático. Para ello debemos aclarar previamente que las obras fantásticas pueden desarrollarse en tres tipos de órdenes distintos:

1) Todo lo narrado entra en el orden de lo natural: Felisberto Hernández, "El cocodrilo", "La casa nueva"; Arístides Fernández, "La mano"; Julio Cortázar, algunos relatos de Historias de cronopios y de famas ("Instrucciones para subir una escalera", "Simulacros", "Tía en dificultades", "Tía explicada o no?", "Las líneas de la mano"); Jorge Luis Borges, "El fin" o "El jardín de senderos que se bifurcan".

2) Todo lo narrado entra en el orden de lo no-natural: Alejo Carpentier, "El viaje a la semilla"; Carlos Fuentes, "En defensa de la Trigolibia"; Juan José Arreola, "El prodigioso miligramo"; Elena Garro, "Un hogar sólido"; Juan Luis Herrero, "No me acaricies, ve-

8 Para aumentar el volumen de las obras incluidas en el género fantástico, Todorov propone fragmentarlas y adjudicar a éste la primera parte del relato mientras no se resuelva la duda, concediendo sólo el final explicativo a lo ma. ravilloso o a lo extraordinario (op. cit., pp. 47-51). Para el comentario sobre su carácter evanescente y la comparación con el presente, véanse pp. 46-47. Conviene destacar, sin embargo, la falacia de la argumentación, porque si el presente en su definición clásica es el límite entre el pasado y el futuro, $y$ para ciertas escuelas filosóficas no existe y todo es pasado o futuro, no debemos olvidar que como categoría gramatical tiene una existencia real y aparece con alto porcentaje de frecuencia en las estadísticas. Esto no debiera dejar de pesar en un autor que tanta importançia da a la correlación literatura y lenguaje para fundamentạ sụs tẹorias. 
nusino"; Julio Cortázar, los relatos que incluyen cronopios, famas y esperanzas, en el libro antes citado.

3) Hay mezcla de ambos órdenes: Eliseo Diego, "La calle de la quimera"; Esther Díaz Llanillo, "Anónimo"; Adolfo Bioy Casares, La invención de Morel; Carlos Fuentes, "El Chac Mool", "Tlactocatzine, del jardín de Flandes"; Elena Garro, "La culpa de los Tlaxcaltecas"; Enrique Anderson Imbert, "El grimorio" o Fuga.

La mezcla de los dos órdenes produce generalmente, por su mera aparición, un fuerte contraste, y presenta la ruptura del orden habitual como la preocupación primordial del relato. Pero no siempre se obtiene o se quiere obtener tal resultado. Pensemos en los cuentos folklóricos y en los cuentos de hadas donde aparecen gigantes, enanos, brujas, ogros, pájaros y fuentes milagrosas, plantas que crecen y suben al cielo. Son los mitos o los herederos del mito que nacieron en un mundo no regido por la ley de la contradicción y han conservado de él la libertad imaginativa. Coincidimos con Todorov en considerar que éstos sí están fueta del género de lo fantástico y los adscribimos al de lo maravilloso, pero no porque se los explique como sobrenaturales sino simplemente porque no se los explica y se los da por admitidos en convivencia con el orden natural sin que provoquen escándalo o se plantee con ellos ningún problema.

No traen, pues, inconvenientes para su clasificación entre lo fantástico los casos en que hay mezcla de los dos órdenes y se insiste en la búsqueda de una explicación sobre esa tuptura de la norma. Más difícil es que se produzca el contraste y se centre en él el interés del texto cuando la obra no se mueve más que en uno de los dos órdenes, y sobre todo no se da explicación que permita realizar el carácter problemático de los hechos.

No intentaremos agotar la lista do los procedimientos que usan los autores en estos casos, pero comentaremos algunos. Por ejemplo, cuando se mueven en el orden natural, como en "Instrucciones para subir una escalera" de Julio Cortázar, basta la descripción minuciosa de los hechos más simples descompuesta en los infinitos movimientos automáti$\cos$ que se realizan cotidianamente, para verlos sujetos a reglas precisas cuya trasgresión amenaza con lanzarnos a lo desconocido, "lo otro" que no se nombra pero queda agazapado y amenazante. Otras veces se cuentan los hechos naturales pero algo trae la presencia de lo irreal en las comparaciones o en las alusiones. Pensemos en "El jardín de senderos que se bifurcan" de Borges, donde el camino que conduce a la quinta 
o la descripción de la obra del antepasado recuerdan infinitos laberintos de espacio y tiempo. Lo mismo ocurre con la "Tía en dificultades" y el relato siguiente "Tía explicada o no?" de Cortázar, donde la cucaracha patas arriba o la comodidad de dormir de espaldas muy pegado a la tierra aluden a la amenaza de la muerte, la más violenta de las intrusiones de "lo otro" en el orden terreno. Otras veces consiste en recordar una serie de hechos que podrían ocurrir en el mundo pero que nunca ocurren, como en el relato "Maravillosas ocupaciones" del mismo Cortázar, donde se acumulan locamente con el convencimiento que tiene el autor de que "lo verdaderamente ńuevo da miedo o maravilla". ${ }^{9}$ Igual sistema utilizó antes el uruguayo Felisberto Hernández, en su cuento "El cocodrilo", donde el hecho insólito de que alguien se ponga a llorar en los lugares y los momentos más inesperados, por puro gusto de desarrollar a voluntad una capacidad gratuita (aunque a veces le resulte productiva) constituye el centro de la historia. Es "curioso que aparezca allí una explicación parecida a la frase antes citada de Cortázar "Hubiera querido salir de aquella tienda, de aquella ciudad y de aquella vida. Pensé en mi país y en muchas cosas más. $Y$ de pronto, cuando ya me estaba tranquilizando, tuve una idea: '¿Qué ocurriria si yo me pusiera a llorar aquí, delante de toda esta gente?' Aquello me pareció muy violento pero yo tenía deseos, desde hacía algún tiiempo, de tantear el mundo con algún hecho desacostumbrado". Y en otro cuento, "La casa nueva", dice: "Así como mi amigo estaba siempre atento a la aparición de cualquier número, yo estaba atento a la aparición de sentimientos, pensamientos, actos o cualquier otra cosa de la realidad, que sorprendiera las ideas que sobre ellas [sic] tenemos hechas". ${ }^{10}$

De todos modos los cuentos comentados superan la mera extrañeza como elemento imaginativo o como variedad introducida para entretener al lector. Esto ocurre por el carácter sistemático de su desarrollo, lo cual da a toda la línea del relato (mantenida sin salirse de lo terreno) una marcada nota de atención centrada en lo inusitado de cse orden, y

9 La frase figura en el relato "Qué tal, López", Historias de Cronopios y de famas, Buenos Aires, Minotauro, 1962, p. 82. En el mismo libro, otro relato lleva este título revelador "Pequeña historia tendiente a demostrat lo precario de la estabilidad dentro de la cual cteemos existir, o sea que las leyes podrian ceder terreno a las excepciones, azares o improbabilidades, y ahí te quiero ver", p. 72 .

10 Ambos relatos fueron recogidos en Las hortensias, Montevideo, Arca, 1967. La primera cita figura en p. 90 , la segunda en p. 120 . Sus textos son anteriores al de Cortázar, pero éste -que lo admita- ha çonfeşado que sólo Io conoció tardiamente. 
sugiere la amenaza callada del otro o la sospecha de que quizás en este mundo de los hombres no exista ningún orden.

Si consideramos los cuentos que se desarrollan en el orbe sobrenatural (total o parcialmente) nos encontramos con muchos que lo presentan en forma no sorprendente y que no provoca escándalo en el ánimo de los personajes que participan de esas aventuras. Varios procedimientos centran el interés internamente sobre lo problemático de su existencia aunque explícitamente no se haga mención de las dificultades que insertan en la vida normal. Muchas veces es el detalle con que se describe la vida sobrenatural o a-normal lo que hace que se concentre en ella el interés y atraiga la comparación con las categorias humanas, es decir un método parecido al que describimos en el Cortázar de "Instrucciones para subir una escalera", pero aplicado antes a lo cotidiano y ahora a lo irreal. En "El viaje a la semilla" de Alejo Carpentier funciona la minuciosa descripción del proceso del tiempo en orden invertido, desde la muerte al nacimiento, en choque con el orden habitual no mencionado pero consabido; en "El prodigioso miligramo" de Arreola es el mundo de las hormigas el que recibe atención circunstanciada, pero ahora en forma paralela y no invertida en su cotejo tácito con la experiencia humana. En "Un hogar sólido" de la mexicana Elena Garro, lo humano llega al ámbito de los muertos con los recuerdos de los cadávetes y las novedades que aportan los recién enterrados que se incorporan al panteón; en el relato de ciencia ficción del cubano Juan Luis Herrero, "No me acaricies, venusino", son los mismos hombres que se han trasladado alli los que llevan sus odios y sus amores. Es más fácil, cuando están los dos orbes presentes, centrarse en su con. traste o en sus espantosas semejanzas; por ejemplo en "La casa de Asterión" de Borges, donde no importa que no se explique lo sobrenatural y que se acepte la existencia del Minotauro y del Laberinto como un hecho no sorprendente, porque sabemos que no estamos en el terreno del mito o de lo maravilloso en cuanto leemos las reflexiones del monstruo que recuerda haber visto tras las murallas de su palacio un mundo en nada diferente de él.

Pasemos a otro punto en el que disentimos con Todorov: el del análisis del nivel semántico. Todorov trabaja con un método que distingue niveles de análisis tomados del modelo de signo de Morris: la dimensión semántica, la sintáctica y la pragmática. La dimensión semántica está acaparando actualmente la atención de los lingüistas, pero es al mismo tiempo una de las más controvertidas. Esto se debe a que los estudios lingüísticos formalizados deben trabajar con las formalizaciones 
previas de la lógica, pero ésta a su vez ha avanzado más en el nivel sintáctico que en el semántico. Si eso ocurre con la lingǘstica, que dispone de mayor experiencia y de instrumentos ya más probados, debemos esperar que las dificultades se acentúen en el campo de la literatura, donde no se ha intentado un sistema de categorias semánticas coherente. Dentro de lo fantástico, todas las clasificaciones temáticas que ha habido hasta ahora resultan poco satisfactorias (por ejemplo las de Vax, de Penzoldt, de Caillois, etc. y no digamos la tan provisoria de Bioy Casares). ${ }^{11}$ Todorov intenta una sistematización que hay que aclarar que él mismo reconoce como provisoria y sujeta a rectificaciones.

Establece dos grupos que abarcan sin distinción lo fantástico, lo extraordinario y lo maravilloso, y los designa con los pronombres del diálogo: Yo y Tứ.

I) Los temas del Yo tienen como principio la puesta en cuestión de materia y espíritu. Este principio engendra temas fundamentales (causalidad particular, pandeterminismo, multiplicación de la personalidad, ruptura del límite entre sujeto y objeto, trasformaciones de tiempo y espacio, etc.) en una lista no exhaustiva. El Yo se caracteriza por las relaciones estáticas, la percepción y las imágenes de la mirada. Es paralelo a la descripción del psicótico, el drogado y el niño.

II) Los temas del Tú tienen como punto de partida el deseo sexual y engendran los relatos de lo excesivo, la perversión, la crueldad, la violencia, la muerte, el vampirismo, la vida después de la muerte, etc. Suelen set más improbables o extraños que fantásticos. Se caracterizan por las relaciones dinámicas, la acción, las imágenes del discurso. Están más conectados con el deseo, el instinto y el inconsciente del hombre.

Si se miran un poco estas categorías de Todorov no parecen privativas de la literatura fantástica, sino aplicables a cualquier clase de literatura. Además habría que preguntarse si por ser tan inclusivas y generales sirven mucho para el análisis literario.

Proponemos, en cambio, dos tipos de categorías que parecen propias del género fantástico en el nivel semántico.

I) Nivel semántico de los componentes del texto:

11 Véase la revisión de las clasificaciones semánticas que hace Todorov, op. cit., pp. 106-109 y 160-161. La de A. Bioy Casares a que aludimos, figura en el "Prólogo" a la Antología de la literatura fantástica antes citada, pp. 10-14. Par un ejemplo de asistematicidad total en el tratamiento del problema, véase Enilio Carilla, El cuento fantástico, Buenos Aires, 1968, Compendios Nova de Iniciación Cultural, No 54, cap. IV. 
1. Existencia de otros mundos: dioses a poderes maléficos y benéficos; la muerte y los muertos; otros planetas o lugares; mundos de naturaleza indefinida.

2. Relaciones entre los elementos de este mundo, que rompen el orden reconocido: tiempos; espacios; causalidad; distinción sujeto/objeto. Esta última distinción podría comprender los íconos o simulacros: los sueños, los espejos y reflejos, y entre ellos el arte (literatura, teatro, pintura, escultura, fotografía, película); los dobles (desdoblamiento del sujeto, o confusión sujeto/objeto); la rebelión de la materia (inanimado contra animado), de los animales y de las plantas (humano contra no humano)..$^{12}$

II) Semántica global del texto:13

1. La existencia de otros mundos paralelos al natural no hace dudar de la real existencia del nuestro, pero su intrusión amenaza con destruirnos o destruirlo. No se duda de que seamos seres vivos, de carne y hueso, pero se descubre que hay fuerzas no conocidas que nos amena. zan ("El Chac Mool", de Carlos Fuentes; Las fuerzas extrañas de Leopoldo Lugones; "Insolación", "El fantasma", "El síncope blanco" de Horacio Quiroga).

2. Se postula la realidad de lo que creíamos imaginario y por lo tanto la irrealidad de lo que creemos real. Por deducción lógica o por contagio del mundo del misterio se llega a dudar de nuestra propia consistencia. Lo otro nos "contagia de irrealidad", como dice Borges (pensemos en "El oxolotl" o "La noche boca arriba" de Julio Cortázar y en toda la obra de Macedonio Fernández) ${ }^{14}$

Queda, por último, preguntarnos algo más sobre el destino del cuento fantástico. Muchos piensan en la desaparición o el debilitamiento del género por diversos motivos: porque el ámbito de lo desconocido se reduce cada vez más con los avances de la ciencia, porque el psico-

12 Algunos de los temas incluidos en el grupo 2 se interpretarán como pertenecientes al grupo 1 , si se deben a influencias de otros mundos. Pensemos, por ejemplo, en cambios en el tiempo o en el espacio que impliquen visitas a regiones infernales o celestes, o intervenciones diabólicas o divinas; también en los temas del doble o en las rebeliones de animales que concluyan sugitiendo la acción diabólica o personificando a la muerte.

13 En mi "Introduccion" a La literatura fantästica en Argentina, México, Imprenta Universitaria, 1957 (obra escrita en colaboración con Emma Speratti Piñero) ya adelanté esta posible clasificación en pp. XIII-XIV:

14 Para las concepciones de Borges y Macedonio Fernández, en parte coinci. dentes y en parte divergentes, véase mi obra citada, pp. $43-44$ y 54-56. 
análisis ha acabado con ciertos tabús que alimentaban lo fantásico, porque la creciente laificación del mundo está reduciendo el campo de lo reli. gioso, que en una época fundó el mito, lo maravilloso y luego lo fantástico. De todos modos el aumento de la irreligiosidad, la liberación de los complejos secretos, la reducción lógica a que la ciencia somete lo ilógico aparencial, no podrán nunca concluir con el reducto de lo desconocido, explicar todo de modo que nada quede inexplicable. Aun suponiendo eso, el miedo a la muerte inevitable continuará alimentando la posibilidad de imaginaciones fantásticas como alimentó los mitos.

Otras dos amenazas se han encontrado para el género. Una nace de problemas socio-políticos, la otra de cuestiones puramente literarias. Refiriéndose a esta última Todorov denuncia en el género una incongruencia de naturaleza. Nace de buscar su fundamentación en el interior del texto, pero con rasgos que son externos a lo literario, de basarla en la oposición normal o a-normal que es propia del mundo exterior y no de la literatura, donde nada es verdadero o falso, real o irreal, natural o sobrenatural, y donde todo es ficción. Dice Todorov que al enfatizarse el carácter literario (es decir, de hecho con palabras) de la literatura, tiene que decaer el género fantástico. Sin embargo habria que pensar que como el canto del cisne, que alcanza cimas excelsas antes de morir, la literatura fantástica ha alcanzado ejemplos extremos en esta época de la "literaturidad" pura. Buena parte de ellos los ha conseguido ahondando su propia naturaleza, es decir, siendo vehículo de la rebelión de su mundo ficticio, que viola el orden terreno.

Por otra parte, los preocupados por problemas sociales, tan acuciantes en nuestra época, acusan de escapista a esta literatura y anuncian su desaparición por obsoleta, por no reflejar los problemas humanos más urgentes, por ser un arte burgués. A ellos habría que recordarles que los teóricos del marxismo no rechazaron por ese motivo a lo fantástico. Lukács, que niega el carácter realista de un mundo delineado con detalles naturalistas incapaces de expresar las fuerzas motrices esenciales de la historia, encuentra natural que "los relatos fantásticos de Hoffmann y Balzac representen ejemplos de literatura realista, porque en ellos, gracias a la exposición fantástica, estos elementos esenciales aparecen destacados. La concepción marxista del realismo afirma que el arte debe hacer sensible la esencia". ${ }^{15}$ Esta posición o la de un Julio Cortázar que cifra la función revolucionaria del artista en revolucionar

${ }^{15}$ En "Introducción a los escritos de estética de Marx y Engels" (hemos manejado la recopilación italiana Il Marxismo e la critica lettevaria, Torino, Piccola Biblioteca Einaudi, No 43, 1964, p. 47). 
el ámbito de las formas o la de un Umberto Eco que asigna ese poder revolucionario a la destrucción y creación de nuevos lenguajes, abren también al género otras posibilidades bajo el signo de lo social, siempre que lo fantástico sea una puesta en cuestión de un orden viejo que debe cambiar urgentemente.

ana maría Barrenechea

CICE, Instituto Di Tella, Buenos Aires 
